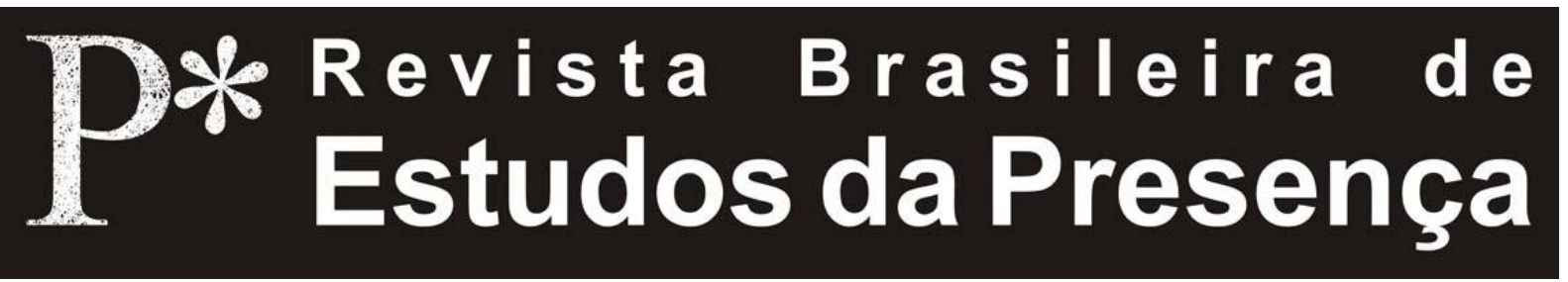

\title{
A Intimidade e a Busca de Encontros Reais no Teatro
}

\author{
André Carreira \\ Universidade do Estado de Santa Catarina - UDESC
}

RESUMO - A Intimidade e a Busca de Encontros Reais no Teatro $^{1}$ - $\mathrm{O}$ artigo reflete sobre os elementos da intimidade na cena contemporânea, considerando isso como uma marca de um teatro que buscar transpor as fronteiras do teatro realista. $\mathrm{O}$ texto ainda propõe uma discussão relacionada com o lugar do espectador em uma cena que valoriza o pessoal e o autobiográfico.

Palavras-chave: Intimidade. Teatro Contemporâneo. Presença e Compartilhamento.

ABSTRACT - The Intimacy and the Searcht of Meetings in the Theater - This paper reflects on the elements of intimacy in the contemporary scene considering it as a mark of a theater that looks beyond the borders of the realistic theater. The text also proposes a discussion about the audience's place in a scene of the personal and autobiographical.

Keywords: Intimacy. Contemporary Theater. Presence and Shearing.

RÉSUMÉ - L'intimité et la Recherche des Rencontres Réel au Théâtre - Cet article réfléchit les éléments de l'intimité dans la scène contemporaine, en considérant cette intimité comme une facette d'un théâtre qui cherche à transposer les frontières du théâtre réaliste. Le texte propose également une discussion sur la place du spectateur dans une scène qui valorise le personnel et l'autobiographique.

Mots-clés: Intimité. Théâtre Contemporain. Présence et Partage. 
A necessidade de a cena teatral reconquistar lugares de importância no campo cultural tem produzido inúmeros movimentos que buscam uma cena na qual os limites entre o privado e o público se aproximam de forma extrema. Vários são os espetáculos ou performances nas quais o medo, a solidaridade, o amor, o perverso, as histórias íntimas e pessoais estão expostos. Espetáculos no qual a exposição do artista em um ato de desnudamento de seus fóruns mais íntimos constitui o eixo do acontecimento.

Estou falando de apresentações frente às quais somos todos, de uma forma ou outra, atores de dramas reais. Situações cênicas que nos convocam a experimentar a intimidade como material dramatúrgico e a decifrar os códigos que vinculam vida real e ficção.

Observando esse fenômeno, é inevitável perguntar por que essa busca do íntimo, do quase confessional no teatro? O que impulsiona um autor, um artista, um ator ou uma atriz de teatro a explorar uma cena na qual joga a realidade, e um alto nível de explicitação do pessoal, um teatro no qual a intimidade é o elemento vincular? O que buscam os artistas ao oferecer à audiência segredos pessoais nesse território no qual sempre se está frágil? $\mathrm{O}$ que busca o público que escolhe este tipo de produção? O que sustenta a realização desses eventos presenciais nos quais operam tanto tecidos pessoais como ficcionais, nos quais se tensam a performance social e a performance estética, o ser sujeito e, ao mesmo tempo, narrador de sua condição de pessoa?

Questões como estas também poderiam ser propostas para os participantes de realities shows, ou de alguns filmes e séries televisivas, nas quais o elemento do real cumpre um papel central. Mas, nesses casos, a resposta parece mais fácil, pois se trata de circunstâncias nas quais mediam o dinheiro e a fama, e todo tipo de benefício que pode ser associado com esses contextos mediáticos.

Essa resposta sobre o mediático é apenas uma aproximação simples a uma realidade muito complexa, pois existe uma nova subjetividade em um mundo mutável. Ainda assim, no que se refere ao ambiente dos 
meios de comunicação de massas, o sentido comum encontra razões que se referem diretamente ao universo do capitalismo e seu mercado da fama. E isso parece justificar todo tipo de excesso.

Além de uma suposta moda do teatro verdade, cabe dizer que a exposição do pessoal na cena nos põe frente a uma problemática de difícil abordagem, apesar de que esse seja um aspecto central a ser analisado quando refletimos sobre uma grande quantidade de projetos de encenação na contemporaneidade. Ainda poderíamos visitar um mundo da arte verdade, onde podemos encontrar exemplos extremos, como é caso do artista espanhol David Nebreda e sua hiperexposição. Não é preciso ir a tais fronteiras, pois este texto se propõe a refletir sobre uma cena que se reconhece como teatral.

A visitação ao território da intimidade e a exposição do pessoal na cena teatral sugere perguntas tais como: este tipo de teatro seria um capricho de estilo ou um projeto estético definido como uma estratégia de mercado? Ou, ainda, uma resposta a um tempo sem segredos? Ou, como apressadamente pensarão alguns, será uma prática característica da pós-modernidade? Seria isso apenas uma evidência a mais do encontro entre a linguagem teatral e os procedimentos da cultura do espetáculo, na acepção de Guy Debord?

Considero o lugar do ator/performer dentro desse contexto - que se pode chamar de teatro do real -, como elemento crucial para a reflexão. Especialmente com o objetivo de discutir porque o real tem tido uma presença significativa na cena teatral. Tomo como ponto de partida as reflexões do pesquisador espanhol José Sánchez, que diz:

André Carreira, A Intimidade e a Busca de Encontros Reais no Teatro

A criação cênica contemporânea não ficou alheia à renovada necessidade de confrontação com o real que se manifestou em todos os âmbitos da cultura durante a última década. Essa necessidade tem dado lugar a produções cujo objetivo é a representação da realidade em relatos verbais ou visuais que, não por reduzir o representável ou assumir conscientemente um determinado ponto de vista, renunciam à compreensão da complexidade. Mas, também a iniciativas de intervenção sobre o real, já seja na forma de atuações que tentam converter o espectador em participante de uma R.bras.est.pres., Porto Alegre, v.1, n.2, p. 331-345, jul./dez., 2011. 
construção formal coletiva, ou na forma de ações diretas sobre o espaço não delimitado pelas instituções artísticas (Sánchez, 2007, p. 76).

A partir da observação de Sánchez podemos identificar três tipos de ações relacionadas com o real e o teatro: representação da realidade; compreensão do real; intervenção sobre o real. Esta última inclui também a transformação do espectador em sujeito ativo do ato teatral.

A hipótese que orienta este texto vincula, no teatro, a exposição do público com a busca de um espaço político vital para um teatro que se faz à margem do sistema do entretenimento. Mas, este teatro tão pouco está isento de ver seu projeto ideológico corroído pela hiperutilização de imagens do real, e pelo desaparecimento dos cantos reservados da intimidade.

A arte, superando a discussão sobre suportes e linguagens, abriu uma fronteira que permitiu avançar muito no que se refere à reflexão sobre as condições de produção e circulação. Talvez por isso a arte contemporânea pareça mais interessada em refletir sobre os processos de mediação e de subjetivação, de tal forma que se produzem experimentações cada vez mais relacionadas com as dimensões autobiográficas.

A aproximação entre o pessoal e o público na cena deve ser relacionado com a busca de novas funções para o teatro, especialmente a partir dos anos 80. A perda de lugares políticos de referência deu impulso a um teatro no qual prepondera a necessidade de autoexpressão, como forma política. $\mathrm{E}$ isso implicou em uma radical aproximação do público com o privado, pois o político se materializou, em grande medida na experiência pessoal, no registro corporal. Este período esteve marcado, como diz Sánchez, por uma necessidade de se recuperar a intersubjetividade perdida, de tal forma que uma atuação desde o real e dentro do real surgiu como forma de reorganizar as identidades pulverizadas pelo mediático (2007). Mas, esse projeto nasceu consciente da impossibilidade de ser completado. De todos os modos, representou, e representa, uma tentativa de resposta à completa dissolução dos efetivos intercâmbios políticos e 
afetivos que caracterizam nossa época e que contaminam o teatro ${ }^{2}$.

Podemos pensar esses movimentos como respostas determinadas por uma urgência. Assim se manifestaram artistas que não viram outro caminho senão o de levar sua arte ao estado da confissão, no meio de uma cultura que parece haver destruído toda a possibilidade de privacidade, ainda que isso soe como paradoxal.

De uma forma ou outra, o teatro busca cumprir seu mandato fundamental, isto é, se fazer como ação transformadora. Mandato imperativo para aqueles que decidiram que a eficácia como mercadoria e entretenimento já não é suficiente para o acontecimento teatral.

Atuando em um campo distinto do entretenimento, os criadores, repetidamente, se encontram órfãos de funções que possam ser mensuradas, e de uma eficácia que possa ser confirmada. No entanto, o desejo de realizar algo concreto com o teatro não morreu, apesar da evidente corrosão do teatro como ferramenta política.

A potência de eficácia transformadora, e a busca de alternativas que caracterizam o teatro da última década, explicita esta tensão de forma frequente. A exploração das tensões entre o público e o privado é resultante do predomínio de abordagens que refletem a experiência imediata como matéria prima da cena. Frente ao vazio político, a crise da eficácia da cena, os limites do pessoal surgiram como fronteira proibida a ser compartilhada com a audiência, como o real possível e verdadeiro. O teatro contribuiu assim para reforçar a percepção dissociada entre a realidade e o real. No contexto da espetacularização extremada a experiência como espetáculo poderia ser um recurso válido para o contato com o real.

Sánchez reivindica a leitura de Maryvone Saison, que em 1998, em Os teatros do real expressou a preocupação característica dos anos 90 por recuperar a capacidade de relação com o real. Obviamente, isso supõe colocar em dúvida a própria noção do real, pois cabe questionar se esta relação se daria por meio da experiência imediata, como sugere Baudrillard, ou 
haveria um real reconhecível desde a fala da história que pediria a construção de realidades, e portanto $\mathrm{o}$ reconhecimento de um real oculto (Sanchez, 2007, p. 16).

Este tempo de incertezas conceituais, e de deslocamentos de paradigmas, propicia as condições básicas da hipervalorização do pessoal na cena, e reforça o lugar político do corpo na atualidade. Uma vez deslocada a política do campo específico da luta de classes, da vigência das narrativas, se reforçaram as correntes que puseram o indivíduo no centro da cena. A crise das instituições questionou o lugar do corpo, e, como afirma Zygmunt Bauman:

O corpo e suas satisfações não se fizeram menos efêmeros desde o tempo em que Durkheim elogiou as instituições sociais duradouras. O obstáculo, no entanto, é que tudo - e principalmente aquelas instituições sociais - se fez ainda mais efêmero que o "corpo e suas satisfações". A duração da vida é uma noção comparativa, e o corpo mortal é agora, talvez, a mais longeva entidade a vista (de fato, a única entidade cuja expectativa de vida tende a crescer ao longo do tempo). O corpo, pode-se dizer, se fez o único abrigo e santuário da continuidade e da duração; seja o que seja que signifique o "longo prazo", dificilmente excederá os limites impostos pela mortalidade corporal (Bauman, 2000, p. 43).

Quando todas as narrativas morrem, ou todas são válidas ao mesmo tempo, ressoa a experiência individual como outra possibilidade. Mas, também ressoam os simulacros das cópias sem matrizes. O corpo, e sua materialidade, o contato com o afetivo e a possibilidade da experiência sugerem algo mais sólido em um mundo da liquefação, e isso reforça o trabalho sobre objetos pessoais, e a vida real como texto. Por isso, ainda que se possa perceber a perda de espaços de um teatro que se autodenomina confissional ou autobiográfico, não é provável que a atração pelos elementos do real na cena se desvaneçam. É preciso lembrar que, atualmente, uma das matérias centrais das relações interpessoais parecem propostas pelas ferramentas da internet chamadas redes sociais. Quantos artistas ou grupos ainda não têm seus proprios espaços no Facebook, Twitter ou no Orkut?

Além das necessidades que caracterizam o campo

André Carreira, A Intimidade e a Busca de Encontros Reais no Teatro

R.bras.est.pres., Porto Alegre, v.1, n.2, p. 331-345, jul./dez., 2011.

Disponível em http://www.seer.ufrgs.br/presenca 
dos realizadores, haveria que perguntar também que tipo de espetacularização busca o público do teatro. Que tipo de cena responde aos desejos desta audiência de começo de século, educada para ver o real como espetáculo, e para compreender o pessoal como público? Como o teatral convive com a espetacularização da vida privada, e descobre seus próprios espaços para lidar com a explicitação do íntimo? A audiência buscaria uma cena na qual encontraria os artistas desvestidos, em certo grau, das máscaras de estilos, ou encontraria histórias como uma fala do real; histórias contadas por atores desde um lugar próximo e próprio, uma alternativa ao mediático. Isso poderia significar um espaço alternativo de intimidade, ainda que muito restrito em relação a todos os fóruns públicos do privado. O único que a faria particular seria a presença performativa como certeza do compartilhamento. Como diz o personagem Expósito em El Líquido Táctil de Daniel Veronese "[...] somente no teatro se está no aqui e agora... por isso não há cães no palco [...]" (Veronese, 1997, 59).

Para o teatro do século XXI a presença do público transcende o fato da audiência como um espectador em sua condição básica, pois o que se busca é, em primeiro lugar, um cúmplice do processo de enunciação, que se projeta além dos códigos comunicacionais, pretendendo estabelecer uma classe de conexão que se aproxima dos materiais do ritual. Como afirma Richard Schechner:

$\mathrm{O}$ evento teatral inclui audiência, performers, palco ou o texto dramático (na maioria dos casos), texto performático, estímulo sensorial, delimitação arquitetônica ou alguma forma de demarcação, equipamentos de produção, técnicos. Isso é assim para um teatro sem matrizes e para o teatro do mainstream, de eventos casuais, à intermidia até "produção de peças". Um contínuo de eventos teatrais que se mescla com o seguinte: vida "impura - eventos públicos, manifestações; intermedia - happenings; teatro ambiental; teatro ortodoxo - arte "pura" (1994, p. XIX).

O contexto da tensão entre a vida impura e uma arte pura representa o terreno concreto da realização cênica. E, por isso, por mais que o verbo compartilhar seja repetido exaustivamente entre as pessoas do teatro, 
este parece não perder seu valor como mote da cena atual. Compartilhar as experiências é a prática social que identifica projetos artísticos comprometidos com as possibilidades de mudanças. Portanto, a audiência e os performers com suas práticas culturais devem ser entendidos como sujeitos desse teatro do real.

Ainda que não se possa vincular esse teatro de forma direta com a concepção de uma arte relacional, proposta por Nicolas Bourriaud, pois, naquela estética o que importaria seria, principalmente, a interação no contexto social no qual se faz a arte, ao focalizar as relações humanas como matéria da arte o autor define os vínculos entre o artista e seu público como o lugar da produção de sentidos. Esta superação daquele objeto estético separado do ato político da convivência, permitiria pensar as experiências individuais como instrumentos da construção de significados coletivos, e até redimensionar a participação do público como suporte das propostas artísticas, e os processos de realização que obrigatoriamente se combinam com a exibição. Com esta perspectiva podemos repensar o teatro e seus vínculos com o real.

Quando me refiro a uma cena da intimidade, estou falando, grosso modo, de um teatro feito nas margens, de um teatro que se faz para pequenas audiências, para um público de teatro, e para pessoas interessadas em experiências. Isso não se deve ao fato de que a matéria da intimidade não interesse às formas associadas ao mainstream, mas, sim, porque é no teatro que se define como experimental, onde estas formas têm maior presença. Apesar de que exista uma linha de fronteira entre um teatro da experiência e o teatro de entretenimento, é importante dizer que o material da intimidade não é exclusivo de um teatro não comercial, ainda que no campo do teatro de entretenimento a intimidade dos famosos, como dado real, é o material mais ambicionado pelos meios e pelos espectadores.

Por outro lado, a ampla maioria do teatro que segue persistindo além das fronteiras de comércio do entretenimento, isto é, através de um sem fim de coletivos e projetos teatrais que exploram o campo da linguagem 
como um permanente reinventar o teatro, volta a colocar a discussão da função e da necessidade do teatro na contemporaneidade.

Considerando estes elementos, é possível dizer que não haveria espaço para uma linguagem artística na qual não se introduza sempre o elemento autobiográfico, ainda que mais não seja, porque a presença mesma do artista se denuncia como vida real realizando a arte. Pode nosso mundo da espetacularização não perceber sempre o artista como sujeito social, isto é, como um sujeito real que atua frente a nós? Estamos falando de práticas que efetivamente produzem objetos artísticos definidos, ainda que reforcem o valor do intercâmbio social como centro do acontecimento.

O lugar do espectador como testemunha representa a contra cara da invenção do ator moderno ${ }^{3}$. A situação na qual este teatro põe o público é um elemento fundamental da renovação teatral, pois condiciona toda a produção de sentidos e todo o processo criador ao elemento relacional. Não podemos pensar a ideia de um ator compositor sem imediatamente pensar em uma audiência autora. Esta autoria do leitor, delimitada anteriormente pela semiótica, ganha no teatro contemporâneo a particularidade de ser uma presença compartilhada, e de ser resultado de um encontro que é sustentado pelos níveis ficcionais do acontecimento, ao mesmo tempo em que não pode deixar de reconhecer-se real. Aquilo que ocorre na cena sempre compromete o ator como sujeito vivente, e o público tem consciência que sua presença também mobiliza os atores como partícipes da cerimônia espetacular.

Isso se deve, principalmente, ao fato de que este teatro se constrói supondo que o principal elemento da criação teatral é aquilo que se produz entre os performers e os espectadores. Mas, um entre que não é produzido apenas pelo nível narrativo do texto dramatúrgico, se não especialmente pela condição do ato humano do representar ao vivo frente ao outro, e de reconhecer o outro como componente ativo.

O tecido invisível das relações concretas está diretamente vinculado com a percepção do outro como

André Carreira, A Intimidade e a Busca de Encontros Reais no Teatro

R.bras.est.pres., Porto Alegre, v.1, n.2, p. 331-345, jul./dez., 2011.

Disponível em http://www.seer.ufrgs.br/presenca 
sócio na produção de sentidos. Cabe recordar que a premissa fundamental da renovação stanislaviskiana é a introdução do acontecimento real na experiência criadora dos atores.

Neste contexto de recepção, existiria um gozo particular em sentir-se testemunha de algo real, no pensar-se convidado a observar o que seria proibido, isto é, alguns elementos da vida íntima do performer. Para além de algum escândalo que uma cena do real possa apresentar, a oferta mais tentadora dessa cena é a verdade, ou melhhor, a intimidade como matéria que reposiciona o espectador como partícipe de uma experiência. A testemunha é aquele sujeito que se apodera da experiência do outro, pois ao presenciá-la se faz responsável da mesma, estando comprometido na experiência inicialmente alheia. É importante notar como o papel do ator, nestes casos, se projeta de forma heróica no sentido que a mitocrítica atribui ao termo.

Os mitemas que podemos relacionar com a figura do ator reforçam a ideia da separação desde em relação à sociedade, um sujeito que se isola, para poder retornar e dialogar com o social, como faz o asceta. Podemos ver nas práticas grotowskianas o paradigma de ator héroi, quando o mestre polonês fala do ator santo. Um ator que se desnuda em função do encontro com o Outro, e faz desse encontro um contínuo do desnudar-se, porque não se trata apenas de um signo do experimentado anteriormente, mas sim, que é a própria experiência do proceso (Carreira; Vargas, 2008).

O discurso que propõe o desfazer-se dos elementos artificiais da arte supõe a possibilidade do descobrimento de uma nova realidade pessoal que é base da re-ligação entre o performer e aqueles que estabelecem contato com seu ato criador vivencial na cena. Existe neste modelo a busca da verdade pessoal como instrumento do vínculo interpessoal. $\mathrm{O}$ ato heróico aparece também nos escritos de Artaud, pois este supõe que fazer teatro é realizar uma contaminação, como ação determinada por seu compromisso do ator/atriz como portador de uma nova lógica para o mundo.

Esta abordagem da atuação faria do teatro um

André Carreira, A Intimidade e a Busca de Encontros Reais no Teatro

R.bras.est.pres., Porto Alegre, v.1, n.2, p. 331-345, jul./dez., 2011.

Disponível em http://www.seer.ufrgs.br/presenca 
lugar no qual se poderia compartilhar a experiência da enunciação da linguagem artística com os performers. Pois, se veria a operação criadora em curso, e, ao mesmo tempo, seria possível ler o plano ficcional. Frente ao espetáculo teatral o público não pode resguardar-se em uma confortável posição de quem apenas assiste a uma história, dado que em toda cena sempre se vê os procedimentos de forma clara e explícita. $\mathrm{O}$ teatro não possui os instrumentos técnicos que o cinema ou a televisão têm para produzir a sensação da completude do realismo. O teatro não pode velar a fabricação de si mesmo. O teatro está condenado ao elemento do real, ainda que seja apenas no plano da emissão do discurso, pois sempre vemos parte do não discurso. É um ator que entra ou sai do palco, uma luz que é acendida, a iluminação que deixa na penumbra parte da cenografia que momentaneamente não se usa. Uma infinidade de acontecimentos que recordam a fabricação da cena.

Também se deve considerar essa perspectiva na hora de dimensionar-se o valor do real como elemento significante no teatro. Parto de um nível básico de que o real da realização cênica é importante para o público; por isso, se observa como se dá a explicitação ou evocação do real, particularmente, o pessoal aprofunda a importância do espetáculo teatral como prática social.

Dessa forma aparecem articulações de ordem afetiva com os espectadores que buscam comprometê-lo intensamente com a construção dos sentidos da encenação. Quando as barreiras entre personagens e performers parecem apagadas o espectador se situa em um lugar comprometido. Por isso, vários dos espetáculos do real parecem acurralar o espectador, ou roubar-lhe a pura condição de espectador, instalando-o em um espaço no qual não pode escapar daquelas sensações que impõe o real como registro.

Os discursos dos artistas cuja produção podem ser enquadradas dentro de um teatro que dialoga com o real, parecem relacionados à necesidade de buscar elementos que permitam uma criação, uma atuação, uma espetacularidade, que produza conexões vinculantes com a audiência. Isto é, um teatro realizado desde um lugar 
mais distanciado da representação e muito mais próximo da apresentação.

Um exemplo concreto dessa prática seria o teatro performativo que pode ser identificado como forma cênica que se mobiliza nesse território fronteiriço do real e do ficcional:

$\mathrm{O}$ teatro performativo - aquele que rechaça o textocentrismo, propõe uma relação igualitária entre as distintas linguagens da cena, uma inter relação artística forte, singulariza mais o teatro de apresentação que a representação de uma história, o ator e os recursos atorais de que o personagem - incrementa a teatralidade porque não oculta os procedimentos. Pelo contrário faz chocar o real contra o realismo como estética e dessa maneira expande os limites do teatro, o faz cruzar as fronteiras tradicionalmente estabelecidas e encontrar, e mesclar-se com outras expressões artísticas (Sagaseta, 2007, s. p.).

Neste sentido, pode-se dizer que, devido à inflação do real, até espetáculos marcadamente comerciais, como aqueles estruturados a partir da presença de um ator ou atriz conhecidos por meio da televisão, podem explorar esse terreno, pois, em muitos casos, importa muito mais ao público estar em contato com a presença real e viva da figura mitificada do que o espetáculo como linguagem. $\mathrm{O}$ ver o sujeito da adoração pode significar mais que todo o espetáculo como experiência de consumo ${ }^{4}$. Pode se dizer que eventualmente vale mais ver o mito que inscrevê-lo dentro de um processo de enunciação ficcional. Ver a grande figura na cena é também reivindicar um elemento do real como ponto principal do consumo do espetáculo como mercadoria. Opera neste caso uma sensação de intimidade com o referente mediático.

$\mathrm{Na}$ introdução de seu livro The radical in performance (1999) o teatrista inglês Baz Kershaw se pergunta "[...] quais são as condições para que as performances radicais prosperem?". Em seguida, o autor diz que:

[...] o lugar do teatro nas sociedades pós industriais parece cada vez mais comprometido, e tanto seu sucesso, como seu

André Carreira, A Intimidade e a Busca de Encontros Reais no Teatro

R.bras.est.pres., Porto Alegre, v.1, n.2, p. 331-345, jul./dez., 2011.

Disponível em http://www.seer.ufrgs.br/presenca 
potencial de radicalidade foram colocados em dúvida [...]. Mas, enquanto o teatro majoritariamente se fez uma mercadoria marginal no mercado cultural, a performance emergeu como central para a produção da nova desordem mundial, um processo chave em praticamente todo domínio sócio político do mundo mediatizado (Kershaw, 1999, p. 5).

Isto talvez explique o fato de que o teatro, e especialmente o teatro do real, tenha quase se mimetizado com a linguagem da performance. Fazendo-se, assim, herdeiro de experiências nas quais os limites entre o pessoal e o ficcional estão apagados, esfumados em uma névoa produzida pela aura do artista como principal elemento vinculante da experiência estético política; a cena do pessoal, do autobiográfico, propõe o extremo da intimidade como radicalidade cênica.

Não é de surpreender que Kershaw tenha subintitulado sua introdução como Patologias da esperança, pois, desse modo, expressa esse forte desejo de efetividade que corta todo o campo teatral: sua potência de eficácia e transformação. Continuamos carentes de uma definição clara de nosso lugar na cultura, especialmente em um tempo cujo pragmatismo nos põe no depósito das inutilidades. O teatro que prolifera é o das margens, uma miríade de experiências teatrais variadas, entre as quais estão as formas do autobiográfico e íntimo.

No entanto, a carência do reconhecimento de uma função clara para o teatro é um elemento chave que o define na atualidade, e é, também, uma força que produz sua condição labiríntica. Esta classe de vazio permanente não é pura inércia, é um vazio que provoca a criação e estimula buscas. Com diz Veronese, o teatro é uma arte da falta, e seria esta falta o que nos empurra para as fronteiras do que fazemos como linguagem artística. Ao explorar estas linhas fronteiriças, o teatro vislumbrou os traços das artes visuais como referência de material criador e pensamento estético, e deu um passo significativo em direção às formas performativas. 


\begin{abstract}
Notas
${ }^{1}$ Este texto é um desenvolvimento do texto Tensiones en la Frontera de lo Público e y lo Provado y el Trabajo del Actor, que faz parte do livro A Veces me pregunto por qué sigo bailando, organizado por Óscar Cornago (Madri, 2011, Editorial Con Tintas me tienes).

${ }^{2}$ Neste sentido, vale a pena observar que Baz Kershaw destaca o fato de que: "Faz tempo que a ideia de um teatro político tem estado em crise. Pós-modernismo e teorias relacionadas com esse pensamento, de forma profundamente ansiosa, estabeleceram noções do que seria 'política' no teatro, segundo as quais o 'teatro político' foi definido a partir de sua relação com a esquerda ou com ideologias socialistas ou marxistas. $\mathrm{O}$ teatro de direita, no entanto, não seria considerado político. O problema agora é agravado porque as ideologias progressistas e esquerdistas parecem estar em declíno, mas ainda mais porque pela nova promiscuidade da política. Desde que o pessoal se transformou em político, nos anos 60, o político encontrou espaços nos mais diversos cantos da cultura. Identidade política, o campo político, corpo político, política sexual a política é agora ambigua e pode ser identificada em todo teatro e toda performance. Tal promiscuidade, portanto, gera uma nova classe de incerteza" (1999).

${ }^{3}$ A invenção da noção de ator do último século é a proba mais contundente deste movimento. Este ator compositor enunciado por Stanislavsky foi sendo moldado na linha da tradição como agente primeiro e objeto focal do acontecimento cênico.

4 Como aponta Baudrillard, na era dos simulacros mais vale a foto de um grande monumento histórico que a experiência real de caminhar por entre suas paredes.
\end{abstract}

\title{
Referências
}

BAUMAN, Zygmunt. Liquid Modernity. Cambridge: Polity Press, 2000.

BOURRIAUD, Nicolas. Relational Aesthetics. Dijon: Les presses du réel, 2002.

CARREIRA, André; VARGAS, Antonio. "Heroe, Actor y Teatro de Grupo". In: PELLETTIERI, Osvaldo (Org.). Huellas Escénicas. Buenos Aires: Galerna, 2007. P. 76-89.

CRUZ, Manuel. Hacia dónde va el Pasado. El Porvenir de la Memoria en el Mundo Contemporâneo. Barcelona: Paidós, 2002.

DERRIDA, Jacques. Writting and Difference. London: Routledge, 2001.

KERSHAW, Baz. The Radical in Performance (Between Brecht and Baudrillard). London: Routledge, 1999.

KIRBY, Michael. A Formalist Theatre. Philadelphia: University of Pennsylvania Press, 1990.

SAGASETA, Julia Elena. "Teatro Performático y Mirada Social. Sobre De mal en peor de Ricardo Bartís. Julia Elena Sagaseta". Territorio Teatral, Buenos Aires, n. 1, s. p., 2007.

SANCHÉZ, José Antonio. Prácticas de lo Real en la Escena Contemporánea.

André Carreira, A Intimidade e a Busca de Encontros Reais no Teatro

R.bras.est.pres., Porto Alegre, v.1, n.2, p. 331-345, jul./dez., 2011.

Disponível em http://www.seer.ufrgs.br/presenca 
Madrid: Visor, 2007.

SCHECHNER, Richard. Environmental Theater. New York: Applause, 1994.

VERONESE, Daniel. Cuerpo de Prueba. Buenos Aires: Libros del Rojas, 1997.

André Luiz Antunes Netto Carreira é professor do Programa de Pós-Graduação da Universidade do Estado de Santa Catarina, pesquisador do $\mathrm{CNPq}$ e diretor do grupo teatral Experiência Subterrânea de Florianópolis www.experienciasubterranea.com e do grupo Teatro que Roda de Goiânia.

E-mail: andre.carreira@udesc.br

Recebido em Julho de 2011

Aprovado em Setembro de 2011

André Carreira, A Intimidade e a Busca de Encontros Reais no Teatro

R.bras.est.pres., Porto Alegre, v.1, n.2, p. 331-345, jul./dez., 2011.

Disponível em http://www.seer.ufrgs.br/presenca 